Full length research article

\section{EXPERIMENTAL ESTIMATION OF CHALLENGE OF A NATURAL POPULATION OF GLOSSINA PALPALIS PALPALIS R-D (DIPTERA:GLOSSINIDAE) ON CATTLE IN THE SOUTHERN GUINEA SAVANNA, NIGERIA.}

\author{
${ }^{*}$ A.B. Ahmed'; S.N. Okiwelu² \& P.M. Dede ${ }^{3}$ \\ ${ }^{1}$ Department of Biological Sciences \\ Kaduna State University \\ P. M. B. 2339, Kaduna, Nigeria \\ ${ }^{2}$ Department of Animal and Environmental Biology \\ University of Port Harcourt \\ Rivers State, Nigeria. \\ ${ }^{3}$ Department of Vector \& Parasitological Studies \\ Nigerian Institute for Trypanosomiasis Research \\ PMB 2077, Kaduna, Nigeria \\ *(Corresponding author) \\ adoahmed2001@yahoo.com
}

\begin{abstract}
The challenge posed by Glossina palpalis palpalis Robineau-Desvoidy 1830 to cattle was studied in a riverine forest of Manchok, Kaduna State, Nigeria. The challenge was estimated indirectly from entomological parameters using the number of flies biting the host and the proportion of flies that are potentially infective. Trypanosome infection rates of $26 \%$ and $24.3 \%$ were recorded in flies sampled from several sites in the dry and wet seasons. From the 134 flies that landed to bite, it was estimated that each animal received an estimated 11 and 15 mean bites per day in the dry and wet season respectively out of which approximately 3 and 4 harbour infections. This means that each animal host received an estimated total infective bite of about 15 (range 0.5-4.1/hr) and 19 (range 0.9-6.6/hr) during the dry and wet seasons, equivalent to 2.96 and 3.8 infective bites per day. Of the estimated infective bites, 12.6 and 2.2 were due to T. vivax Ziemann 1905 and T. congolense Boaden 1904 received during the dry season while 17.3 and 1.5 were received during the wet season. Activity of flies started at $09.00 \mathrm{hr}$ during the wet season and one hour later during the dry season. For both seasons, diurnal activity was less pronounced in the early morning $(06.00-11.00 \mathrm{hr})$ than mid (11.00-15.00hr) and late afternoon (15.00-18.00hr), and so was the number of potentially infective bites. The number of potentially infective flies feeding per day (06.00-18.00hr) was higher and more consistent during the wet season than in the dry season but the difference was not significant $(P>0.50)$. The results suggest a high tsetse challenge in the area which is exacerbated by several factors including the synchronized activity of the flies and grazing herds, frequency of visit to riverine habitats of the vector and duration of contact between vector and host.
\end{abstract}

Key words: Tsetse fly challenge, Trypanosoma vivax, T. congolense, cattle, Nigeria

\section{INTRODUCTION}

The simulation of biological matters are not always perfect (Friend et al. 1997). This is one reason why the estimation of trypanosomiasis risk is complex (Rogers 1988) and often difficult to measure with accuracy in the field. Most of the present day models made use of powerful assumptions that have important implications for the broad epidemiology of the disease.
Previous attempts at estimating the level of this factor, included both the direct approach, when tsetse were observed feeding on animals (Cawdery 1958) and the indirect methods, involving the evaluation of some epizootiological parameters such as fly density, trypanosome infection rates in the flies, proportion of meals taken from cattle, feeding success, number of flies and proportion that are potentially infective (Leggate \& Pilson 1961; Snow \& Tarimo, 1983; Leak et al. 1993; Baylis 1997). These various approaches provided useful information towards understanding the component of the risk factor in disease transmission.

Animal trypanosomiasis is a serious constraint to profitable livestock development in Kaura Local Government Area of Kaduna State, Nigeria (Agu et al. 1983; Maikaje 1998; Ahmed 2003). Because of its critical importance in the epidemiology of the disease and in the planning of effective control strategies, the level of tsetse challenge on cattle was estimated for the area. The following experiment measures, indirectly; the number of flies biting, and the proportion that are supposed to be potentially infected. It is hoped that information obtained would lead to proper definition of the trypanosomiasis risk level as a prelude to identifying an area to be targeted by the area-wide concept of the Pan African Tsetse and Trypanosomiasis Eradication Campaign (PATTEC)

\section{MATERIALS AND METHODS}

Study area

The study was conducted in Manchok (80.30E and 90.40 N), Kaura Local Government Area (LGA) of Kaduna State, Nigeria, within the northern edge of the Southern Guinea Savanna zone (Keay 1953). Details of the study have been described (Ahmed 2003). Two white zebu yearling heifers were used for the experiments, one during the peak of the dry season (January) and the other at the peak of the wet season (July). The animals were tethered in the relic forest between $06.00-18.00 \mathrm{hr}$ for 5 consecutive days during the months of the study and provided with food and water.

\section{Fly catching}

Tsetse flies were collected by two fly catchers with hand nets as soon as they landed on the animals to bite. The time of capture, sex and tenerality of the flies were recorded. Each caught fly was then marked with acrylic oil paint on the thorax (Jackson 1953) and released. A different colour was used daily.

\section{Estimation of trypanosome infection rates in the flies}

Because of the limitations of the technique used it was not possible to directly determine the infection rates from the flies caught off the experimental animals. This was estimated through the dissection of 180 flies trapped from several sites within the LGA using Nitse trap (Omoogun 1994) and Biconical trap (Challier \& Larvessiere 1973). The trypanosoma species were identified by the rapid method of Penchenier \& Itard (1981). 
Analysis

A simple indirect method was used to estimate the challenge posed by tsetse on cattle during the study using two epidemiological parameters, namely:

i. the number of flies biting (obtained from the number landing)

ii. the proportion of flies that are potentially infective (Leggate \& Pilson 1961) (obtained from the number that are non-tenerals)

This approach utilized the assumption of Corbet \& Smith (1974) that:

(1) The number of tsetse landers on the animal hosts is equivalent or consistently proportional to the number of biters.

(2) The potentially infective component of the landing fly population is directly proportional, though not necessarily exactly equivalent to the number of nontenerals.

All experiments were terminated at $18.00 \mathrm{hr}$ daily when visibility becomes poor to identify flies perching on the experimental animals.

\section{RESULTS}

A total of 140 tsetse flies landed on the animals during the experiment, 59 during the dry season and 81 in the wet season. Six of the total landings were tenerals and were excluded from the analysis. A recapture rate of $20.1 \%$ was recorded.

\section{Diurnal activity pattern of the flies}

Figs 1 and 2 show the diurnal activity pattern of the tsetse population recorded between $06.00-18.00 \mathrm{hr}$. The result shows that tsetse flies challenge grazing animals for several hours in a day. The challenge was greater during the wet season than the dry season: the wet season activity showed two peaks of fly activity one at $10.00 \mathrm{hr}$ and another at $15.00 \mathrm{hr}$ while the dry season activity showed three peaks at $10.00,13.00 \mathrm{hr}$ and 15.00hr.

\section{Trypanosome infections in the flies}

All the dissected flies had mature infections that invaded the hypopharynx. T. vivax constituted $85.0 \%$ and $9.2 \%$ of the infections in the dry and wet seasons respectively while $T$. congolense formed $15.0 \%$ and $8.0 \%$ during same period. $T$. brucei Plimmer \& Bradford 1899 infections were not encountered. (Table 1).

\section{DISCUSSIONS}

The results suggest that the livestock at Manchok are exposed to a high daily trypanosome challenge both during the dry and wet seasons.

The population of tsetse landing on the experimental animals apparently contained large numbers of non-tenerals. The low proportion of tenerals in the sample suggests that the population contained older individuals and therefore potentially more efficient as vectors. It has been established that trypanosome infection rate in tsetse is positively correlated with the age of flies (Jordan 1974; Kaminsky 1986; Ahmed et al. 2000). The estimated age of G. P. palpalis in the study area is 34 days for males and 32 days for females (Ahmed 2003), old enough to maintain the transmission cycles of $T$. vivax and $T$. congolense observed in the study.

The mean numbers of tsetse flies landing on one cattle per day were 11 and 15 during the dry and wet seasons respectively, lower than the 289 flies observed landing/feeding on one ox in Zimbabwe during the dry season (Leggate \& Pilson 1961). However, cognizant of the low fly density at Manchok, the estimated proportion of infected flies of approximately 3 and 4 were probably indicative of higher risk than the 28 observed by Leggate \& Pilson (1961).

TABLE 1: SEASONAL INFECTIONS RATES OF G. P. PALPALIS WITH TRYPANOSOMES AT MANCHOK

\begin{tabular}{|c|c|c|c|c|c|c|}
\hline \multirow[b]{2}{*}{ Season } & \multirow[b]{2}{*}{ Sex } & \multirow{2}{*}{$\begin{array}{l}\text { No } \\
\text { dissected }\end{array}$} & \multirow{2}{*}{$\begin{array}{l}\text { No } \\
\text { infected }\end{array}$} & \multicolumn{3}{|c|}{ Trypanosoma species (\%) } \\
\hline & & & & vivax & congolense & brucei \\
\hline \multirow{3}{*}{ Dry } & $M$ & 27 & $5(18.5)$ & $4(80.0)$ & $1(20.0)$ & $0(0)$ \\
\hline & $\mathrm{F}$ & 50 & $15(30.0)$ & $13(86.7)$ & $2(13.3)$ & $0(0)$ \\
\hline & Total & 77 & $20(26.0)$ & $17(85.0)$ & $3(15.0)$ & $0(0)$ \\
\hline \multirow{3}{*}{ Wet } & $M$ & 38 & $7(18.4)$ & $6(85.7)$ & $1(14.3)$ & $0(0)$ \\
\hline & $F$ & 65 & $18(27.7)$ & $17(94.4)$ & $1(5.6)$ & $0(0)$ \\
\hline & Total & 103 & $25(24.3)$ & $23(92.0)$ & $2(8.0)$ & $0(0)$ \\
\hline \multicolumn{2}{|c|}{ Total } & 180 & $45(25.0)$ & $40(88.9)$ & $5(11.1)$ & $0(0)$ \\
\hline
\end{tabular}




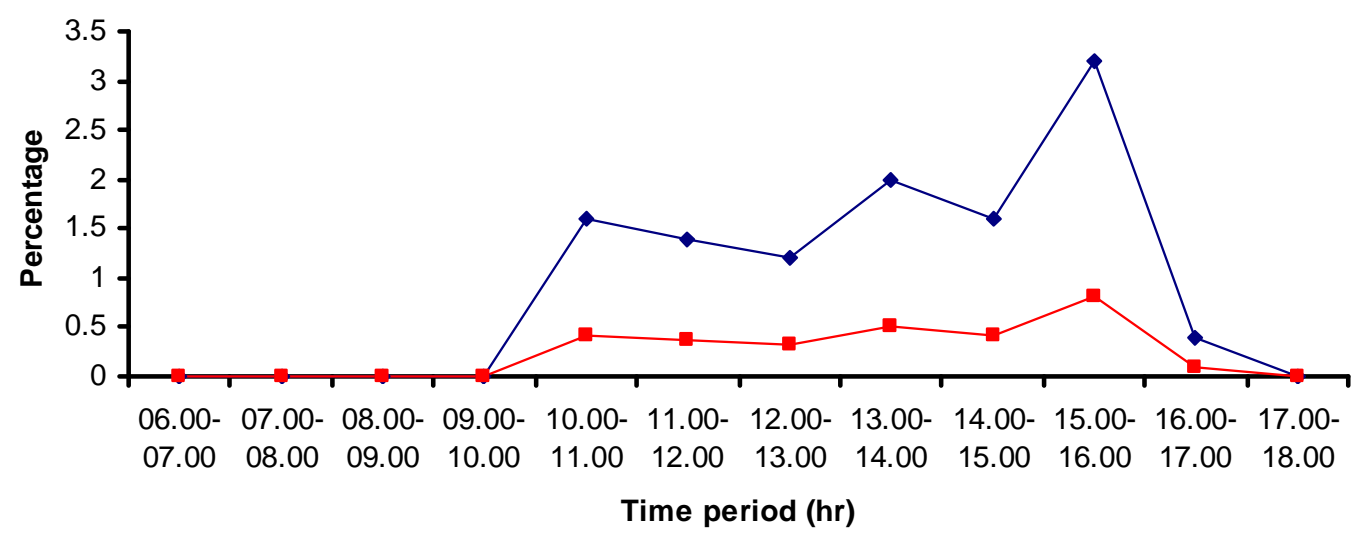

FIG.1 DIURNAL ACTIVITY PATTERN OF G. P. PALPALIS SHOWING MEAN NUMBER OF FLY LANDERS AND THE ESTIMATED PROPORTION INFECTED DURING THE DRY SEASON

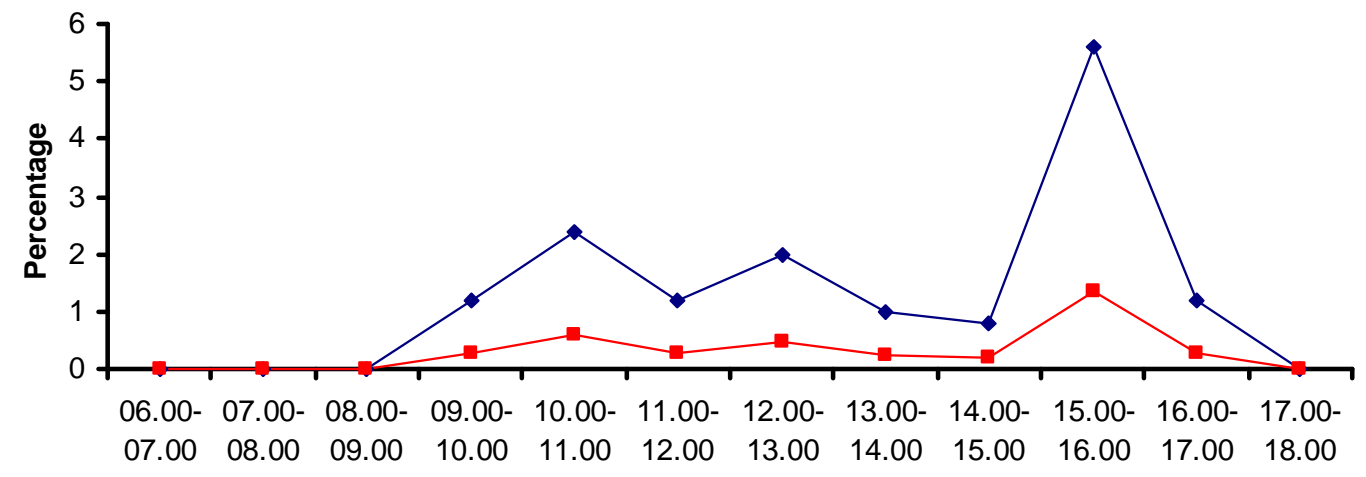

Time period (hr)

FIG.2 DIURNAL ACTIVITY PATTERN OF G. P. PALPALIS SHOWING MEAN NUMBER OF FLY LANDERS AND THE ESTIMATED PROPORTION INFECTED DURING THE WET SEASON 
In both seasons, fly activity starts between $09-10 \mathrm{hr}$ and remain sustained until evening. The delay in the commencement time of fly activity observed during the dry season was probably because of the relatively low morning temperatures during the period as previously observed by Tenabe (1983) in the same ecological zone. The sharp decrease in activity which commences between $15.00-16.00 \mathrm{hr}$ in both dry and wet seasons may be due to combined effects of falling temperatures and onset of darkness (Page 1959 a \& b). The general sustained high activity pattern exhibited by the flies may indicate persistent attacks to seek blood meals due to hunger. Ahmed (2003) had earlier confirmed a high Mean Hunger Stage (MHS) value in the population, indicating that the population was in a hungry state.

Since the infection rate of tsetse is among several factors used to determine the trypanosomiasis risk level of an area (Jordan 1974), the high infections rates recorded in this study portray Manchok as a high trypanosomiasis risk area for livestock development. The estimated mean proportion of 3 and 4 potentially infected flies biting one cattle each day during the dry and wet seasons respectively, supports the assertion.

Although the presence of $T$. brucei in the area was confirmed only from cattle, its absence in the flies is not surprising because detection of natural infections in tsetse is rare (Baldry 1969; Jordan 1974; Ahmed et al. 2000), especially by the conventional diagnostic dissection method utilized in this study (Lloyd \& Johnson 1924; Penchenier \& Itard 1981).

Results from oral interviews of 20 randomly-selected herdsmen (Ahmed 2003) revealed that the epizootiology of the disease is also influenced by management practices of the pastoralists and farming activities of the local farmers: eighty per cent of the respondents indicated that they take their stock for watering along streams and other riverine natural habitats of tsetse at least 3 times daily (i.e. Morning, afternoon and evening). This close interaction between tsetse and cattle suggest that animals are exposed to natural infective bites during each visit to the riverine habitats. The risks increased during the peak dry season (November-March), because the animals spend more hours grazing in the vicinity of such streams where pasture and water are accessible.

Flies trapped and dissected from 22 sites within the study area revealed trypanosome infection rates of $10.0 \%$, the lowest value of $4.3 \%$ recoded in Mafam village and the highest value of $18.8 \%$ observed in Malagum village (Ahmed 2003). If the proposed assumptions used in this experiment are valid, the result suggest that the natural herds of grazing cattle in the experimental area are experiencing a high tsetse and trypanosome challenge, similar to the measured values, which probably accounts for the endemicity of animal trypanosomiasis in the area.

\section{REFERENCES}

Agu, W. E.; Katab, U. Z.; Haruna, E. A.; Ayandele, J.; Aina, A.; Baah, M. M. \& Adamu, S. 1980. Field survey for bovine trypanosomiasis in parts of Kaduna and Plateau States. In NITR Annual Report, 1980-83. Himma Press Ltd, Kaduna, Nigeria.

Ahmed, A. B. 2003. Population ecology of Glossina palpalis palpalis Robineau-Desvoidy 1830 (Diptera: Glossinidae) in relation to animal trypanosomiasis in the southern guinea savanna, Nigeria. Ph.D Dissertation, University of Port Harcourt, Nigeria, pp 378 .

Ahmed, A. B.; Omoogun, G. A. \& Shaida, S.S. 2000. Trypanosome infections in Glossina species at the Kainji wild life Partk, Nigeria. Entomological Society of Nigeria Occasional Publication 32:57-62

Baldry, D. A. T. 1969. Distribution and trypanosome infection rate of G. m. submorsitans along trade cattle route in southwestern Nigeria. Bulletin Entomological Research 58:537

Baylis, M. 1997. The daily feeding rate of tsetse (Diptera; Glossinindae) on cattle at the Galana Ranch, Kenya and comparison with trypanosomiasis incidence. Acta Tropica 65:8196.

Cawdery, M. J. H. 1958 Estimation of trypanosome challenge. Annual Report East African Trypanosomiasis Reseasrch Organisation No. 8: 1956-1957.

Challier, A \& Karvessuere, C. 1973. Un nouveau piege pour la capture des Glossines (Glossina: Diptera, Muscidae) description et essays ur le terrain. Cashier ORSTOM . Series Entomologie Medicale et Parasitologie 11:251-162.

Corbet, P. S. \& Smith, S. M. 1974. Diel periodicities of landing of nulliparooous and parous Aedes aegypti $(\mathrm{L})$ at Dar es Salaam, Tanzania. (Diptera, Cullicidae). Bulletin Entomological Research $111-121$

Friend, A.D.; Stevens, A.K.; Knox, R.G. \& Cannell, M.G.R., 1997. A process-based, biogeochemical, terrestrial biosphere model of ecosystem dynamics (Hybrid v3.0). Ecological Modelling, 95: 249-287

Jordan, A. M. 1974 Recent developments in the ecology and methods of control of tsetse flies, (Glossina spp) (Diptera: Glossinidae)-a review. Bulletin Entomological Research 63:361399. 
Kaminsky, R. 1986. Infection rates of tsetse flies (Diptera: Glossinidae) with trypanosomes in the Liberian rain forest during the dry season. Animal Research \& Development 23:56-70

Leak, S. G. A.; Woudyalew, M.; Authie, E.; D'leteren, G. D. M.; Peregrine, A. S.; Rowlands, G. J. \& Trail, J. C. M. 1993. Epidemiology of bovine trypanosomiasis in the Ghibe valley, southwest Ethiopia. Tsetse challenge and its relationship to trypanosome prevalence in cattle. Acta Tropica. 53:121-134.

Leggate, B. M. \& Pilson, R. D. 1961. The diurnal feeding activity of Glossina pallidipes Aust in relation to trypanosome challenge. Bulletin Entomological Research 51:697-704.

Lloyd, L, \& Johnson, W. B. 1924. The trypanosome infections of tsetse flies in northern Nigeria. Bulletin Entomological Research $14: 265-288$

Maikaje, D. B. 1998. Some aspects of the epidemiology and drug sensitivity of bovine trypanosomoses in Kaura Local Government Area of Kaduna State. Ph.D Thesis, Ahmadu Bello University, Zaria, Nigeria. pp 147.

Omoogun, G. A. 1994. The design and construction of the Nitse trap. Insect Science \& its Applications 15 (4/5): 535-539.
Page, W. A. 1959a. The ecology of G. palpalis (R-D) in southern Nigeria. Bulletin Entomological Research 50:617-631.

Page, W. A. 1959b. The ecology of Glossina longipalis Wied. in southern Nigeria. Bulletin Entomological Research 50:595.

Penchenier, L. \& Itard, J. 1981. A new technique for the rapid dissection of salivary glands and gut of tsetse. Cashier ORSTOM Series Entomologie Medicale et Parasitologie 19:55-57.

Rogers, D. J. 1988. A general model for the African trypanosomiases. Parasitology 97:193-212

Snow, W. F. \& Tarimo, S. A. 1983. A quantification of the risk of trypanosomiasis infection to cattle on the South Kenya coast. Acta Tropica 40:331-340

Swallow, B. M. 2000. Impact of trypanosomiasis on African agriculture. PATT Technical and Scientific Series 2. FAO Rome.

Tenabe, S.O. 1983. A study of the diurnal activity of Glossina $p$. palpalis (Diptera: Glossinidae) in Niger State using Challier and Larveissiere trap. Nigerian Journal of Entomology 4:81-87. 